\title{
Comparing the lifestyles of victims: A routine activity theory assessment of repeat victimization in Canada
}

\author{
Zavin Nazaretian* and Chivon Fitch ${ }^{\dagger}$
}

\begin{abstract}
This paper simultaneously explores the relationship between social status, routine activity theory, and repeat victimization. This study compares the effects of lifestyle with key social status variables like gender, race, and sexuality, on varying degrees of victimization to answer the question: do routine activities or social status predict repeat victimization? This research is a secondary data analysis using two waves of the Canadian Victimization Survey from 2004 and 2009. Both a logistic regression and multinomial logistic regression are used to analyze the possible causes of repeat victimization. Overall, social status is influenced by lifestyle when predicting victimization; however, key social status variables predict high levels of victimization such as identifying as gay or lesbian or being an Aboriginal Canadian. The most powerful indicator of victimization was if a victim had been previously arrested themselves. The results of this study suggest that, while lifestyle is a strong predictor of victimization, minority groups are still at risk of being victimized at higher levels.
\end{abstract}

Key Words Social status; LGBT.

\section{INTRODUCTION}

The relationship between Routine Activity Theory (RAT), social status, and repeat victimization is complex. The three areas are rarely studied simultaneously; thus, little is known about the interaction of repeat victimization with social status (i.e., income, sex, age, completion of high school, race, Aboriginal Canadian status, sexuality, nativity, and an urban-rural identifier) and RAT. By studying repeat victimization, an examination of the causes of victimization can be explored across varying levels of severity and propensity. The majority of empirical tests on prior victimization use binary measures of victimization. In this paper, three levels of victimization will be studied: a binary measure of occurrence, a measure contrasting repeat and single victimization, and a measure of high repeat versus repeat victimization. The measures each paint a different picture of victimization and the implications of differing measurements warrant exploration. Both social status and routine activities will be examined to verify whether the previous weight given to RAT in studies can be maintained as victimization levels increase. One would assume that if RAT successfully explains singular victimization, then as levels of victimization increase, the variables associated with RAT would also become stronger predictors of victimization. If routine activities theory cannot account for repeat victimization, it could raise serious questions regarding the strength of the theory. Does RAT predict multiple victimizations or does one's social status predict multiple victimizations? The present study offers insight into this question to help clarify the relationship between RAT, social status, and repeat victimization.

This research will address the following three research questions. First, how is social status (i.e., race, socio-economic status, gender, and sexuality) related to the probability that an individual will suffer from repeat criminal victimization? Second, do lifestyle and opportunity differences (specified by RAT) explain social status differences in repeat victimization? Third, are social status characteristics moderated by the effects of routine activities on victimization?

\section{Background}

Repeat victimization refers to a pattern whereby the same person, household, or place is victimized more than once. Because of the prevalence of repeat victimization, a small proportion of victims represent a disproportionate amount of victimization (Pease, 1993; Perreault \& Brennan, 2010;

Correspondence to: Zavin Nazaretian, Adrian College, 110 S. Madison St., Adrian, MI 49221, USA. E-mail: znazaretian@adrian.edu.

To cite: Nazaretian, Z., \& Fitch, C. (2021). Comparing the lifestyles of victims: A routine activity theory assessment of repeat victimization in Canada. Journal of Community Safety and Well-Being, 6(2), 56-65. https://doi.org/10.35502/jcswb.181

@ Author(s) 2021. Open Access. This work is distributed under the Creative Commons BY-NC-ND license. For commercial re-use, please contact sales@sgpublishing.ca. gevblshIng Published by SG Publishing Inc. CSKA Official publication of the Community Safety Knowledge Alliance. 
Nazaretian \& Merolla, 2013). For example, in Canada, just $13.5 \%$ of victims represent $54 \%$ of all victimization (Gabor \& Mata, 2004). Repeat victimization has been of particular interest to crime prevention researchers and criminal justice practitioners since the 1970s and has gained greater exposure in the 1980s as a result of the Kirkholt Burglary Prevention Project in the United Kingdom (Forrester et al., 1988). Kirkholt is a public housing community in England that suffered from rates of burglary far higher than the national average. The study focused on individuals who had already been victims of burglary, finding that repeat victimization was more probable than first-time victimization. The crime prevention project implemented crime reduction techniques based on reducing the opportunity for crime to occur in places it already had. This study demonstrated that cost-effective methods of crime prevention could be developed by focusing on those individuals, households, and places that are most likely to be repeatedly victimized (Forrester et al., 1988). As well as aiding in developing crime prevention efforts, research on repeat victimization has also helped researchers calculate more accurate rates of crime and has influenced the way measures of victimization have been constructed in surveys (Laycock, 2001; Nazaretian \& Merolla, 2013; Lauritsen et al., 2012). Research on the rates of crime that include repeat victimization demonstrates victimization surveys underreport crime. Specifically, in Canada, they underreport violent crime more than property crime (Nazaretian \& Merolla, 2013).

To date, the bulk of theory testing for repeat victimization involves repeat property crime (Farrell et al., 1995; Johnson et al., 1997; Tseloni et al., 2004; Johnson, 2008). More repeat victimization theory testing is needed for nonproperty-related victimization. Research indicates that repeat victimization is most prevalent for the most serious violent crimes such as sexual assault and assault (Farrell, Tseloni, \& Pease, 2005; Pease, 1993). Previous research on the causes of repeat victimization uses opportunity theories focusing primarily on the environment in which a crime occurs as the most important influence on crime prevalence (Felson \& Clarke, 1998; Tilley et al., 2002). Although criminologists target multiple aspects of the criminal environment, the most prominent theory used in studies of repeat victimization is RAT. Routine activities theory dictates that the most significant cause of crime is the opportunity for it to occur, defined by three factors. For a crime to occur there must be a lack of capable guardianship, a motivated offender, and a suitable target (Cohen \& Felson, 1979). The last situational factor "a suitable target" has also been operationalized as including the lifestyle of the victims. For instance, individuals who are victimized repeatedly might frequent dangerous areas or otherwise engage in behaviours that increase their risk of criminal victimization. Miethe et al. (1987) explain that RAT incorporates lifestyle theory, but it is a more complete explanation of victimization because it considers both the lifestyle of the victim and the environment of victimization. The proportion of individuals who are repeatedly victimized is seen as evidence that criminal victimization is based on opportunities, because these individuals have specific attributes that make them a consistent target for criminal offenders (Tseloni et al., 2004; Farrell et al., 1995).

Much of the existing research on repeat victimization has focused on police presence in high crime areas, the physical characteristics of high crime areas, and how the mapping of crime patterns can be used to focus police efforts on "hot spots" where a large amount of crime occurs (Farrell \& Sousa, 2001; Farrell et al., 1995; Menard \& Huizinga, 2001; Polvi et al., 1990; Ratcliffe, 2002; Tseloni \& Pease, 2003). The research focused on how to reduce repeat victimization often uses experimental methods that alter the opportunity for a crime to occur by manipulating the physical environment. This research has generally shown that when the opportunity to commit a crime is manipulated, a reduction results (Short et al., 2010). For example, numerous studies have examined parking locations that suffer from repeated car theft. The studies indicate that by increasing surveillance in the area, changing the physical characteristics of the hot spots (lighting) can lead to a reduction in car theft (Levy \& Tartaro, 2009). Additionally, there is little evidence of displacement, or criminal offenders simply choosing new parking lots, because there was no significant increase in car theft in nearby areas (Johnson et al., 2012).

This example of repeat victimization research also showcases two related trends in the field. First, the research in this area tends to be limited to property crime; and second, there is little focus on the impact of social status on the opportunity for crime to occur. The present study will focus on both opportunity and social status to determine whether the same theoretical framework that is often used to explain victimization is useful for explaining repeat victimization. Additionally, this research includes an analysis of both property and violent crime, broadening the previously narrow focus used in other tests of RAT. Research shows that victims of assault and sexual assault are the subpopulations of victims who suffer the highest level of repeat victimization (Farrell et al., 2005). International patterns of repeat victimization indicate that the likelihood of being a repeat victim increases as the severity of the crime increases (Farrell et al., 2005). For instance, Pease (1993) argues that the pattern of repeat victims being subject to violent crimes is so pronounced that he suspects that murder victims would suffer from the highest level of repeat victimization prior to their murder. In general, violent crimes against individuals are more likely to be repeat crimes than are crimes against property (Pease, 1993). The literature on victimization fails to fully explain whether repeat victimization is simply the consequence of the same factors that put one at risk of victimization to begin with or whether it results from a more complex explanation. For example, Lauritsen and Quinet (1995) looked beyond opportunity-based theories of crime and examined the effects of the victim labeling process.

Social status is an important factor to consider when examining repeat victimization as many of the factors that contribute to the notion of social status have been linked to an increased risk of victimization: sex (Johnson \& Sacco, 1995; Fox et al., 2009); race (Peterson \& Krivo, 1999); age (Lauritsen et al., 1992; Sampson \& Laub, 2003); income (Gannon \& Mihorean, 2004; Daly, Wilson, \& Vasdev, 2001); education (Lochner, \& Moretti, 2004, Machin et al., 2011); sexuality (Herek, 1990); nativity (Reitz \& Banerjee, 2007); Aboriginal status (Brzozowski et al., 2006). These variables (as discussed below) are missing in the majority of research on repeat victimization despite it having been demonstrated in previous studies that they predict both criminal offending and victimization. 
This research is of importance to the Canadian population because Canada suffers from high rates of repeat victimization. For instance, in 2004, just $10 \%$ of Canadian crime victims represented $60 \%$ of all criminal incidents (Perreault \& Brennan, 2009). In addition to the skewed amount of crime repeat victimization represents, this effect is exaggerated for the most serious crime types; just two percent of the Canadian population accounted for $60 \%$ of all violent crime victimizations (Perreault \& Brennan, 2009). Given the degree to which repeat victimization plagues Canada, further research is needed to inform policymakers and practitioners interested in implementing crime prevention measures.

A review of the literature in this field will demonstrate two things. First, research that has examined opportunity theories of crime (versus social status) has not used repeat victimization as the dependent variable. Second, research on repeat victimization has not addressed the relationship between social status characteristics and multiple victimizations.

\section{Opportunity Research Missing Repeat Victimization}

While the research focused on repeat victimization has ignored social inequality in its explanation of crime, there is research in the opportunity theory literature that includes inequality. The majority of research in this area comes from lifestyle theory research, but social inequalities are also included in more formal tests of RAT (Cohen \& Felson, 1979). Research in this area has examined the link between inequality and lifestyle. Cohen et al. (1981), in their earlier work, specifically explored the connection between social inequality and predatory victimization. While they found some connection between inequality and victimization, it suggested that path analysis would be a useful tool for explaining crime. For instance, the researchers found that people in their study were racially and economically segregated and that those who live in poor neighbourhoods were both more likely to be a poor minority and more likely to be victimized. However, when they controlled for lifestyle and proximity to poor urban areas, they found that income, race, and gender did not have direct effects on the risk of assault (Cohen et al., 1981). Using a tiered measure of victimization, unlike the Cohen study, may uncover the direct effect or the partial effect of inequality on victimization when controlling for lifestyle. While not directly looking for the effect of inequality on victimization (instead of controlling for it), other research on the topic has placed opportunity above inequality in explaining crime (Jensen \& Brownfield, 1986; Miethe et al., 1987).

One important study on the connection between opportunity theories of crime and inequality is by Cao and Maume (1993). In their research, they found that lifestyle and urbanization were strong predictors of robbery. However, they also found that the influence of inequality on robbery was mediated by lifestyle. The findings suggest that urbanization and lifestyle are not causal elements of victimization but are mechanisms of the effects of social status. Their work prompts further research on the connection between said variables since these relationships are currently underexamined.

While inequality is not the missing variable in lifestyle theory victimization research, the previously discussed studies lack consideration of repeat victimization. The majority of the work cited is American and, until recently, the
National Crime Victimization Survey (NCVS) did not have an easily accessible measure of repeat victimization because multiple victimization incidents were recorded as series of incidents without a record of the exact number of victimizations (Ybarra \& Lohr, 2002). Research in the field of repeat victimization has been met with enough acknowledgment that the United States Census Bureau has been persuaded to change their data collection to better measure exact levels of repeat victimization (Lauritsen et al., 2012). Thus, prior research in this area could not use victimization as a variable with scale. This research not only expands on the work of previous repeat victimization research, but it also expands the research on RAT (target suitability/lifestyle) by adding the variable of multiple victimizations.

To date, one study does account for all three of the criteria: inequality, opportunity theory, and repeat victimization. Tseloni et al. (2004) study residential burglary across three nations: England and Wales, the United States, and the Netherlands. Their research uses a continuous variable instead of a dichotomous one for victimization. The study also tested for opportunity theories of crime while controlling for some variables measuring inequality. One difference in the cited work and this research is the choice of control variables. The race variables they used indicated only whether one was white or not white. In addition to the race variable being limited, the economic variable was not ideal. Instead of measuring the exact income or bracket of income for the participants, their employment status was used. This status indicated whether the participants were unemployed, employed part-time, or employed full-time (Tseloni et al., 2004). The researchers found that opportunity was a much stronger predictor than employment status when predicting repeat victimization. The purpose of the study was to test RAT and Lifestyle theory; thus, it was not designed to test the effect of inequality on victimization. This research builds on their work, using more measures for social status.

\section{Repeat Victimization Research}

The crime pattern referred to as repeat victimization has been documented as a global phenomenon. Every victimization survey, whether it is the Canadian Victimization Survey (CVS), British Crime Survey, NCVS (United States), or the International Crime Victimization Survey (ICVS), shows a pattern whereby a small proportion of victims represent a larger proportion of crime (Farrell \& Bouloukos, 2001). The pattern of repeat victimization is sometimes used to support the notion that criminals capitalize on the same opportunities for those who have been victimized multiple times. The assertion is that the opportunity surrounding certain victims is so great that they are victimized time and time again. Thus, victimization can be attributed to their lifestyle, the environment they live in, or some combination of the two. People who are victimized time and time again are presented as appealing victims. While the connection between opportunity theories of crime and repeat victimization seems obvious, little has been done to explore the connection between social status and repeat victimization.

Repeat victimization literature can be broken down into three categories of research (methodological, prevention/ policy, and theoretical). There is a plethora of research arguing that repeat victimization is an important methodical 
concern for victimization surveys (Planty \& Strom, 2007; Lauritsen et al., 2012). While this research proves repeat victimization should be addressed in the victimization survey methodology, it does not make any inferences about the theoretical connections between repeat victimization and social status or lifestyle factors. However, the literature in this field does emphasize the importance of repeat victimization for victimization research, as it demonstrates how a small number of individuals account for a large proportion of all victims of crime. For example, Planty and Strom (2007) show that if repeat victimization is included in the NCVS, crime rates increase by $62 \%$ in 2000 to as much as $174 \%$ in 1996. This difference in rates can lead to major differences in conclusions about the prevalence of crime in the United States. The authors point out that, in 1996, only 9,969,943 crimes were reported by the government using the NCVS; however, when repeat victimization is included, the number of crimes is closer to 25,546,326. Similar findings have been documented using data from Canada (Nazaretian \& Merolla, 2013) and the United Kingdom (Farrell \& Pease, 2007). Given the effect that repeat victimization can have on crime rates, it is important for scholars to understand the etiology of repeat victimization.

The increases in crime rates found when accounting for repeat victimization are not evenly distributed across all crime types. Instead, research on repeat victimization clearly demonstrates that the more serious crime types in society are more heavily influenced by repeat victimization (Farrell et al., 2005). The ICVS, which surveys 16 countries, demonstrates that violent crime is more prone to repeat victimization than property crime. Based on analysis of victimization across these 16 countries, $43 \%$ of victims of sexual assault and $39 \%$ of assault victims suffer from repeated victimization while only $15.7 \%$ of personal theft and $9.3 \%$ of car theft victims were repeat victims (Farrell et al., 2005).

While excelling in crime prevention and measurement strategies, the field of repeat victimization research has lacked theoretical development. Farrell et al. (1995) clearly outline how the effect of repeat victimization on crime prevention policy has "outpaced" the theoretical understanding. The lack of theoretical development of repeat victimization is surprising since it has such a strong influence on crime rates (Johnson et al., 1973; Zeigenhagen, 1976; Sparks et al., 1977; Hindelang et al., 1978; Feinberg, 1980; Reiss, 1980; Gottfredson, 1984; Farrell \& Pease, 2007; Nazaretian \& Merolla, 2013). The theoretical link between repeat victimization and opportunity theories has more often been assumed rather than tested because of the logical link between opportunity and repeat victimization.

Social status, just like RAT and opportunity theories of crime, has a long history of being linked to victimization. The connection between income and victimization proposed by Gannon and Mihorean (2004) and Daly et al. (2001) demonstrates that a decrease in income is associated with an increase in the likelihood that individuals will be the victims of violent crime. The effect of social status on victimization is not limited to financial inequality but is also established for racial and sexual minorities, as well as for immigrants (Peterson \& Krivo, 1999; Herek, 1990; Reitz \& Banerjee, 2007). Within Canada, governmental research by Perreault and Brennan (2009) demonstrated that Aboriginal people experience high rates of victimization and also have a low social status in the country. This link between the social status of Aboriginal people and victimization is also discussed by Dickson-Gilmore and La Prairie (2005), who identify challenges Aboriginal victims experience as unequal members of Canadian society.

Given the gaps in the research that have been described, this research is warranted. Specifically, this work will look at repeat victimization, RAT, and social status simultaneously to further develop the field's theoretical understanding of why repeat victimization occurs. Not only is it hypothesized that repeat victimization will be better explained by including social status and RAT in a singular analysis but, for the etiology of this crime pattern to be understood, social status cannot be ignored. The environmental context in which crime occurs is shaped by and linked to social status.

\section{METHODS}

\section{Data and Sample}

The data used in this research is taken from the CVS, which is similar to the NCVS and is conducted as part of Statistics Canada's General Social Survey every five years. Respondents selected for the CVS are asked about their experiences with both personal and property crime victimization experiences over the past year (Statistics Canada, 2009). However, one key difference between the CVS and the NCVS is that the CVS asks respondents for the details of up to 20 crimes per crime type. Because of this unique feature of the CVS, it is an ideal dataset to use to study the precursors of repeat victimization. For this research, the samples from the 2004 and 2009 survey periods are combined. These two survey years are identical in content (Perreault \& Brennan, 2010). We combined the 2004 and 2009 sections to obtain an adequate number of individuals at all victimization levels examined. The target population of the survey is members of the Canadian population aged 15 and over who do not live in institutional settings. This population is thus almost identical to the target population of the larger General Social Survey (GSS). For the 2004 survey, 23,766 respondents were included in the sample. For the 2009 survey, 19,422 respondents were included in the sample. The total combined sample includes 43,188 individuals. The response rates are $75 \%$ for 2004 and $61.6 \%$ for 2009 . All analyses are weighted using the Statistics Canada-provided weights that correct for a differential response.

\section{Dependent Variable}

The dependent variable for this study is victimization. Several specifications of this variable are included in the multivariate analyses presented below. In the CVS, the variable total incidents is the rawest measure of victimization. The original variable continuously measured the total number of times an individual in the sample reported being victimized, either for violent or property victimization. Thus, this measure represents the total number of crime incidents reported by the respondent in the survey (Statistics Canada, 2009). Responses to this variable range from 0 to 132 victimization incidents, and the mean number of victimizations for the total sample was 0.63 with a standard deviation of 3.11 (see Table I). The crimes included in this analysis are sexual assault, robbery, physical assault, breaking and entering, motor vehicle theft, theft of household property, vandalism and theft of personal 
TABLE I Sex, Sexuality, and Racial Rates of Victimization

\begin{tabular}{|c|c|c|c|c|c|c|}
\hline & Sample Size & Total Incidents & SD & Victimization & Repeat Victimization & High Repeat \\
\hline Total sample & 43,000 & 0.63 & 3.11 & 27.1 & 10.5 & 3.1 \\
\hline Male & 21,297 & $0.65^{\star}$ & 3.07 & $28.3^{*}$ & $10.9 *$ & $3.2^{*}$ \\
\hline Female & 21,903 & $0.62^{*}$ & 3.16 & 26.0 & 10.2 & 2.9 \\
\hline LGBT & 734 & $1.41^{*}$ & 5.19 & $44.2^{* *}$ & $24.9 *$ & $10.8^{*}$ \\
\hline Heterosexual & 42,466 & $0.62^{*}$ & 3.09 & $25.7^{*}$ & 10.2 & 3.0 \\
\hline White & 35,467 & $0.62^{*}$ & 3.01 & 26.6 & 10.1 & 2.8 \\
\hline Visible minority & 10,152 & 0.69 & 3.75 & 27.1 & 10.7 & 3.3 \\
\hline Aboriginal & 820 & $1.01^{*}$ & 3.08 & $36.8^{*}$ & $17.9 *$ & 6.6 \\
\hline
\end{tabular}

Source: Statistics Canada, GSS Victimization Survey Cycles 18 and 24

$N=43,200$

$* * p<.01$

${ }^{*} p<.05$

property. Prior research has demonstrated that the pattern of repeat victimization is most prominent for those suffering from the most serious crimes, making the combination of these types of crime an acceptable choice (Farrell et al., 2005).

Any Victimization vs. No Victimization. The first dependent dichotomous variable used in this study was any victimization. For this variable, 0 represented no victimization and 1 represented all degrees of victimization. For the total sample, $27.1 \%$ of respondents indicated being victimized (Table I).

Repeat Victimization vs. One Victimization. The dependent variable, repeat victimization, was also dichotomous and, again, used in logistic regression models for the entire sample and five subsamples. The variable was coded as 0 or 1 , with 0 representing one victimization and 1 representing anyone being victimized more than once in the given survey period. Constructing the variable this way made it possible to directly compare singular victims of crime with repeat victims; $38.8 \%$ of the victimized sample indicated that they had been the victim of more than one crime.

High Repeat Victimization vs. Repeat Victimization. High repeat victimization was the third and final dependent variable used in the logistic regression models. The variable is dichotomous, with 0 indicating the individual had been victimized twice within the survey period and 1 indicating that the individual had been victimized three or more times. This variable compared repeat victims of crime with those who suffered high levels of repeat victimization. The cutoff of three victimizations for high repeat status was chosen because the Canadian government currently caps all victimization counts at three for use in the calculation of official governmental statistics (Nazaretian \& Merolla, 2013; Statistics Canada, 2009). Thus, if differences are found between these two categories of victims, the case can be made that Statistics Canada should reconsider the capping level. Of all repeat victims, $11.3 \%$ indicated that they had been victimized three or more times. Table I illustrates the different victimization rates and occurrences based on race, sex, and sexuality and indicates that LGBT and Aboriginal Canadians had the highest rates of victimization at 1.41 and 1.01 incidents, respectively, on average. Looking at the percent of victimization experienced by these different groups, again, LGBT and Aboriginal Canadians experience the highest rates of victimization, at $44.2 \%$ and $36.8 \%$, respectively. In addition to experiencing high rates of victimization, these two groups also experience statistically significantly higher rates of repeat victimization and high repeat victimization: $24.9 \%$ of LGBT Canadians experienced repeat victimization and $10.8 \%$ experienced high repeat victimization, while $17.9 \%$ of Aboriginal Canadians experienced repeat revictimization and $6.6 \%$ experienced high repeat victimization (Table I).

\section{Independent Variables}

The independent variables in this research can be divided into two broad categories. The first category includes variables used to measure social status (see Table II). The variables in this category include income (categorical variable with 13 categories), age, sex $(0=$ Male, $1=$ Female), completion of high school $(0=\mathrm{No}, 1=\mathrm{Yes})$, race $(0=$ Minority, $1=$ White $)$, Aboriginal Canadian status $(0=\mathrm{No}, 1=$ Yes $)$, sexuality $(0=$ Heterosexual, $1=\mathrm{LGBT})$, nativity $(0=$ Canadian born, $1=$ foreign born), and an urban-rural identifier $(0=$ Rural, $1=$ Urban). Of particular interest in this research is the measurement of sexuality. Studying the lesbian, gay, bisexual, and transgender (LGBT) community sets this study apart from most studies; this research utilizes a nationally representative random sample of this population (Statistics Canada $2004 ; 2009)$. Included in our sample is the $1.7 \%$ of the population who self-identified as being LGBT during the survey years. Having access to such a sample in this capacity is uncommon; at present, Canada is one of few nations with a nationally representative victimization survey asking questions about sexuality.

The second category of variables is used to measure RAT. Marital status, previous arrest, crime prevention, evening activities, night work, night travel, and alcohol consumption are all used to measure one's suitability as a target. These variables can also be viewed as lifestyle variables (Table II). The link between lifestyle theories of victimization and RAT is well established and has been discussed in the work of Miethe et al. (1987). Composite variables were constructed to measure capable guardianship and motivated offender. The composite variable for capable guardianship was created by combining five questions that asked respondents about the presence and effectiveness of police in their community. The 
TABLE II Variable information

\begin{tabular}{|c|c|c|}
\hline & Mean/\% & Standard Deviation \\
\hline \multicolumn{3}{|l|}{ Dependent } \\
\hline Victimization & $27.1 \%$ & \\
\hline Repeat victimization & $10.5 \%$ & \\
\hline High repeat victimization & $3.1 \%$ & \\
\hline \multicolumn{3}{|l|}{ Control / Social status } \\
\hline Income & 9.04 & 2.33 \\
\hline Age & 44.53 & 18.18 \\
\hline Female ( $1=$ Yes) & $50.7 \%$ & \\
\hline High school (1=Yes) & $73.5 \%$ & \\
\hline White (1=Yes) & $82.1 \%$ & \\
\hline Aboriginal $(1=$ Yes $)$ & $1.9 \%$ & \\
\hline LGBT (1=Yes) & $1.7 \%$ & \\
\hline Nativity (1=Yes) & $21.9 \%$ & \\
\hline Urban & 3.94 & 1.66 \\
\hline \multicolumn{3}{|l|}{ Routine activity and lifestyle } \\
\hline Capable guardianship & 2.56 & 0.39 \\
\hline Motivated offender & 1.27 & 0.40 \\
\hline Married ( $1=$ Yes) & $50.9 \%$ & \\
\hline Previous arrest (1=Yes) & $5.6 \%$ & \\
\hline Crime prevention & $35.5 \%$ & \\
\hline Evening activities & 25.09 & 35.06 \\
\hline Night work & 8.69 & 16.73 \\
\hline Night travel & 2.27 & 1.01 \\
\hline Alcohol consumption & 3.31 & 1.74 \\
\hline
\end{tabular}

Source: Statistics Canada, Crime Victimization Survey Cycles 18 and 24 $N=43,200$

composite variable motivated offender was created by combining eight questions that asked respondents about the level of visible crime in their community. For example, one of the questions was "How much of a problem are: ... people using or dealing drugs?" (Statistics Canada, 2009).

\section{Analytic Strategy}

Given that the primary focus of this study is to investigate the relationship of the independent variables to low and high levels of victimization, eliminating outliers from the sample to use an ordinary least squares (OLS) regression would have eliminated a central contribution of this study. Thus, victimization was investigated through four specifications of the victimization measure. Three dichotomous non-mutually exclusive specifications of victimization are used with the logistic regressions. Each victimization category included the higher rates of victimization within it. For example, the victimization category included all victims, while the repeat victimization category only included victims who had been victimized more than once. For the multinomial logistic regression, one mutually exclusive categorical specification was used (victimization $=1$, repeat victimization $=2$, high repeat victimization $=3+$ ). Predictably, most Canadians reported little to no victimization, and a small number of individuals reported high levels of victimization, making the variable positively skewed and inappropriate for continuous variable linear modelling techniques (e.g., OLS or quantile regression). In addition to using a multinomial logistic regression, both a negative binomial and zero-inflated negative binomial model were considered. Given that the data focuses on victimization, we do not have a zero-inflated measure, making zero-inflated models less appropriate. Similarly, the data does not reflect overdispersion of the means, making negative binomial models unnecessary (Long \& Long, 1997). After reviewing the structure of the data and considering the intent to compare groups of victims based on governmental techniques of capping victimization, a multinomial logistic model was selected to compare different groups of victims to non-victims. Comparing these groups is necessary due to the governmental analyses treating victims of crime as a single group by capping the dependent variable (Nazaretian \& Merolla, 2013).

\section{RESULTS}

When examining variation in victimization across the entire sample, there were notable differences at all levels of victimization based on elements of social status and opportunity. The first analysis of the effects of social status and opportunity in relation to victimization is a multinomial logistic regression, with the reference category being no victimization. Table III describes the results from these models comparing the three levels of victimization to non-victims of crime. More important for this analysis than singular significant findings were patterns of significance across varying levels of victimizations $(p<.05)$. Several variables are not only significant across the models but have increasing odds ratios, denoting that there is an increase in the variable associated with an increase in the chances of victimization. Of the social status variables, the variables that are significant and have a consistent directional effect across the model are age, Aboriginal status, LGBT, and nativity. As respondents' age increases, individuals are less likely to be the victims of crime. This effect is stronger as the level of victimization goes up. Respondents who identified as Aboriginal Canadians are 1.36 times more likely to be victims of one crime, 1.65 times more likely for two crimes and 1.7 times more likely to be the victims of three or more crimes, even when controlling for social status and lifestyle.

Although previous governmental studies identify Aboriginals as the most victimized minority, LGBT individuals are also a highly victimized group in this sample. Canadians identifying as LGBT are no more likely to be the victim of a singular crime incident; however, they are 1.5 times more likely to be the victims of two crimes and 2.4 times more likely to be victims of three or more crimes. Females and non-Canadian-born residents are less likely to be the victims of repeat crimes. Immigrants to Canada are slightly less likely to be the victims of singular crimes, 0.77 times for two crimes and 0.72 times less likely to be victimized three times or more. Women, who in past studies have been shown to experience more victimization than 
TABLE III Multinomial-logistic regression reference group non-victims

\begin{tabular}{|c|c|c|c|}
\hline & Victims & $\begin{array}{l}\text { Repeat } \\
\text { Victims }\end{array}$ & $\begin{array}{l}\text { High Repeat } \\
\text { Victims }\end{array}$ \\
\hline & $\operatorname{Exp}(B)$ & $\operatorname{Exp}(B)$ & $\operatorname{Exp}(B)$ \\
\hline \multicolumn{4}{|l|}{ Social status } \\
\hline Income & $1.054^{* *}$ & $1.093^{* *}$ & $1.054^{* *}$ \\
\hline Female & $.925^{* *}$ & .946 & $.840 * *$ \\
\hline Age & $.982^{* *}$ & $.976^{* *}$ & $.964^{* *}$ \\
\hline High school & $1.096 * *$ & .966 & $.783^{* *}$ \\
\hline White & $1.101^{*}$ & 1.098 & 1.022 \\
\hline Aboriginal & $1.365^{\star *}$ & $1.648^{* *}$ & $1.708 * *$ \\
\hline LGBT & 1.161 & $1.502 * *$ & $2.393^{*}$ \\
\hline Nativity & $.907^{* *}$ & $.774^{* *}$ & $.716^{* *}$ \\
\hline Urban & $1.081^{* *}$ & $1.114^{* *}$ & $1.087^{* *}$ \\
\hline \multicolumn{4}{|l|}{ Routine activity and lifestyle } \\
\hline Capable guardianship & $.679 * *$ & $.447^{* *}$ & $.265^{\star *}$ \\
\hline Motivated offender & $1.474^{* *}$ & $2.043^{* *}$ & $2.463^{* *}$ \\
\hline Married & .966 & $.810^{* *}$ & $.815^{\star \star}$ \\
\hline Previous arrest & $1.490 * *$ & $1.828^{* *}$ & $2.742 * *$ \\
\hline Crime prevention & $1.686^{* *}$ & $2.563^{* *}$ & $4.501^{* *}$ \\
\hline Evening activities & 1.001 & $1.002^{* *}$ & $1.003^{* *}$ \\
\hline Night work & $1.002^{*}$ & $1.005^{* *}$ & $1.005^{* *}$ \\
\hline Night travel & $1.039 * *$ & $1.085^{* *}$ & 1.045 \\
\hline Alcohol consumption & $1.032 * *$ & 1.019 & $1.071^{*}$ \\
\hline \multicolumn{4}{|c|}{$\begin{array}{l}\text { Source: Statistics Canada, GSS Victimizatic } \\
N=43,200 \\
{ }^{* *} p<.01 \\
{ }^{*} p<.05 \\
\text { Reference Category } 0=\text { No Victimization }\end{array}$} \\
\hline
\end{tabular}

men (sexual victimization), are less likely than males to be victimized when examining both property and violent crime. Specifically, women are almost 0.92 times less likely to be victimized once and 0.84 times less likely to be victimized three or more times.

Beyond the social status characteristics of the victims, there are several opportunity variables that predict victimization. Individuals who experienced victimization are much more likely to indicate that there was a presence of motivated offenders in their community. Victims of one crime are 1.5 times more likely to indicate this, while victims of two crimes are 2 times more likely to cite potential offenders in their community as a problem. Individuals who experienced victimization three or more times are 2.4 times more likely to identify motivated offenders in their community than those who were not victimized (Table III). Unfortunately, the variable representing capable guardianship is not ideal because it is formulated based on the opinion of victims. It stands to reason that someone who has been victimized might see the presence of police in their community as ineffective.

The second strongest relationship from the multinomial logistic regression is the connection between victimization and previous arrests. Individuals who had been arrested in the past are much more likely to be victimized than those who had not been previously arrested. Those who had been victimized once are 1.5 times more likely to have been previously arrested. Those who had been victimized twice are 1.8 times more likely to have been previously arrested. And, finally, those who had been victimized three or more times are 2.7 times more likely to have been arrested than non-victims of crime (Table III).

The final significant variable in the model, which is consistent across all levels of victimization, is the composite variable of crime prevention. Individuals who had been victimized once are 1.7 times more likely to engage in crime prevention strategies than non-victims. Those who were victimized twice are 2.6 times more likely and those who were victimized three or more times are 4.5 times more likely to engage in crime prevention. Initially, the use of the crime prevention variable was assumed to measure some sort of opportunity-reducing techniques by individuals, which would then have a negative relationship with victimization. However, based on the strength of the relationship and the direction of the effect, crime prevention strategies are most likely to be initiated after victimization.

In Table IV, the control/social status variables are first run independently of the opportunity variables (RAT and lifestyle; Model 1), then these variables are added to demonstrate the mediating effect of opportunity on social status (Model 2). Based on Baron and Kenny's (1986) approach to establishing mediation, we determined that social status and lifestyle characteristics were both predictive of victimization. While almost all of the variables predict victimization in both models for single victimization in Table III, when comparing the social status variables in models 1 and 2 , the mediated effect on social status of including opportunity is evident. For example, the effect of education (high school) is completely mediated, and for both of the minority groups in the model, there is a diminished effect (Baron \& Kenny, 1986). When opportunity is added to the model, the effect of being LGBT and having Aboriginal status is reduced, but not completely eliminated.

This same effect is evident when comparing single victims with repeat victims in Table IV: when opportunity is added to the model, the effect of being LGBT on victimization is decreased. In the case of Aboriginal people, the effect is completely eliminated. While the effects of social status are reduced by opportunity for some categories, when looking at LGBT status, for example, opportunity specifically decreases the likelihood of LGBT victimization from $92 \%$ to $42 \%$. Thus, even when controlling for opportunity variables, the LGBT community is still $43 \%$ more likely to experience repeat victimization than the general population.

In the last column of Table IV, fewer variables predict victimization differences between repeat and high repeat victims; however, for those variables that are significant, opportunity mediates the effect of social status. The effects of income, Aboriginal status, and nativity are completely mediated by opportunity. A reduction in the effect of social status is shown for LGBT status and completion of high school. The effect becomes more pronounced for age. Even when accounting for opportunity, then, LGBT status still makes respondents almost 1.7 times more likely to be a high repeat victim than a repeat victim of crime. 
TABLE IV Logistic regression nationally representative sample

\begin{tabular}{|c|c|c|c|c|c|c|c|c|c|c|c|c|}
\hline \multirow[b]{4}{*}{ Social status } & \multicolumn{4}{|c|}{$\begin{array}{l}\text { Victimization } \\
N=43,200\end{array}$} & \multicolumn{4}{|c|}{$\begin{array}{l}\text { Repeat Victimization } \\
\qquad N=11,707\end{array}$} & \multicolumn{4}{|c|}{$\begin{array}{l}\text { High Repeat Victimization } \\
\qquad N=4,536\end{array}$} \\
\hline & \multicolumn{2}{|l|}{ Model 1} & \multicolumn{2}{|c|}{ Model 2} & \multicolumn{2}{|l|}{ Model 1} & \multicolumn{2}{|c|}{ Model 2} & \multicolumn{2}{|c|}{ Model 1} & \multicolumn{2}{|c|}{ Model 2} \\
\hline & $\operatorname{Exp}(B)$ & & $\operatorname{Exp}(B)$ & & $\operatorname{Exp}(B)$ & & $\operatorname{Exp}(B)$ & & $\operatorname{Exp}(B)$ & & $\operatorname{Exp}(B)$ & \\
\hline & & & & & & & & & & & & \\
\hline Income & 1.043 & ** & 1.063 & ** & 1.000 & & 1.027 & $* *$ & .967 & * & .991 & \\
\hline Female & .942 & * & .925 & $* *$ & 1.036 & & 1.028 & & .969 & & .932 & \\
\hline Age & .971 & * & .979 & ** & .982 & $* *$ & .992 & $* *$ & .976 & $* *$ & .984 & ** \\
\hline High school & 1.117 & ** & 1.017 & & .883 & $* *$ & .832 & $\star *$ & .825 & $* *$ & .753 & ** \\
\hline White & 1.072 & & 1.090 & * & .931 & & .978 & & .879 & & .940 & \\
\hline Aboriginal & 1.726 & $* *$ & 1.472 & ** & 1.391 & * & 1.248 & & 1.407 & * & 1.202 & \\
\hline LGBT & 1.861 & $* *$ & 1.401 & ** & 1.921 & $* *$ & 1.428 & $* *$ & 2.410 & $* *$ & 1.694 & ** \\
\hline Nativity & .763 & $* *$ & .856 & $* *$ & .778 & $\star *$ & .876 & * & .755 & * & .888 & \\
\hline Urban & & & 1.090 & $* *$ & & & 1.034 & * & & & 1.008 & \\
\hline \multicolumn{13}{|l|}{ Routine activity and lifestyle } \\
\hline Capable guardianship & & & .544 & $* *$ & & & .569 & $\star *$ & & & .465 & ** \\
\hline Motivated offender & & & 1.730 & ** & & & 1.579 & $\star \star$ & & & 1.554 & ** \\
\hline Married & & & .910 & ** & & & .852 & ** & & & .911 & \\
\hline Previous arrest & & & 1.684 & $\star *$ & & & 1.403 & $\star *$ & & & 1.740 & ** \\
\hline Crime prevention & & & 2.052 & ** & & & 1.755 & ** & & & 2.309 & ** \\
\hline Evening activities & & & 1.001 & ** & & & 1.006 & $\star *$ & & & 1.007 & ** \\
\hline Night work & & & 1.003 & $\star *$ & & & 1.002 & & & & 1.001 & \\
\hline Night travel & & & 1.051 & $* *$ & & & 1.031 & & & & .993 & \\
\hline Alcohol consumption & & & 1.031 & $* *$ & & & 1.001 & & & & 1.042 & * \\
\hline
\end{tabular}

Source: Statistics Canada, GSS Victimization Survey Cycles 18 and 24

${ }^{* *} p<.01$

${ }^{*} p<.05$

\section{DISCUSSION}

As suspected in the case of the models that compare no victimization with single victimization, the majority of the variables were significant. Not only was this due to the large sample size, but this effect is also because they were selected based on their prior significance in previous research and theoretical tests. Of particular interest in this research is the question of whether these variables remain significant predictors of victimization at varying levels of victimization and whether they remain directionally significant.

As victimization became more severe, fewer variables remained significant and even fewer variables remained significant while operating in the same direction. The three social status variables that remained significant across the majority of the models are the completion of high school, age, and LGBT status. Additionally, the effects of lifestyle mediated all three of these variables (Table III). There are also five lifestyle/opportunity variables that remained significant in all of the models: previous arrest, crime prevention, the number of evening activities, capable guardianship, and a motivated offender. For many of the opportunity variables, issues arose concerning dependent versus independent variable confusion. For example, the number of crime prevention strategies one engaged in increased as victimization increased. This indicates that engaging in crime prevention strategies is a result of more frequent victimization, and, in a sense, is ineffective. Other variables where causality was muddled include capable guardianship and motivated offender. It is unclear whether these variables are truly accurate responses by respondents or whether victims' views have been changed by being victimized. For example, did the respondent's view of the police diminish because she or he had been repeatedly victimized, or was a respondent who was repeatedly victimized able to accurately report the quality of policing in their neighbourhood? In future iterations of this research, this could be controlled by comparing victims and non-victims who reside in the same areas for their opinion on policing/capable guardianship.

The most powerful indicator of whether someone would be victimized is having been previously arrested. This vari- 
able could be considered the ultimate lifestyle variable and further strengthens the literature on the victim-offender overlap. While the lifestyle/opportunity variables did not consistently predict victimization through all of the models, they did cause mediation in all of the logistic regressions. So, although these variables did not solely explain victimization, they did rule out certain social status variables. Furthermore, a mediating effect was also noted in the social status variables that remained significant, indicating that victimization is explained by both social status and opportunity simultaneously versus reciprocal causation.

Some of the most compelling findings of this research are the social status variables that remained highly significant in the majority of the models. For example, the predictive power of being gay or lesbian is highly significant in all of the models and not entirely explained away by lifestyle differences. While being Aboriginal was not significant in every model, it was still a strong predictor of victimization, which is in line with Canadian research on victimization (Brzozowski et al., 2006). Further research is needed to understand why certain groups are repeatedly targeted for victimization in Canada, devoid of lifestyle differences that would make them more suitable targets. Future research on this topic should include research with specific subsamples, such as the LGBT or Aboriginal population, to identify the within-group causes/predictors of singular versus repeat victimization.

\section{CONCLUSION}

While our research is a step towards gaining a better understanding of how lifestyle and social status characteristics affect victimization, our study has limitations. First, we are using secondary data provided by the Canadian Victimization Survey. The data is not explicitly designed with the variables of interest in this study in mind. More precise measures could be created to determine with more specificity whether our findings can be replicated. Second, the restricted nature of the data makes it impossible to conduct post hoc analyses: once the researcher left the facility, it was not feasible to return to the data repository to re-run or revisit analyses of interest. If the sample sizes differed between results within 20 respondents, results could not be exported. Finally, the sample size of the data varies from one data collection period to the next. While we expanded our sample size by combining two waves of data, it would be preferable to use waves with higher response rates, if possible. Although the current study and data are not without limitations, they do offer insight into an underexamined and important topic. Further, the results of our study may provide insight into policies and practices that may reduce the risk of victimization and revictimization for vulnerable populations living in Canada. Taken in combination with other studies on this topic, we are hopeful that policymakers can use these findings to address risk factors and design policy for the at-risk populations identified in this study. Victimization in Canada is not evenly distributed and our crime prevention strategies need to be reflective of this in both scope and funding.

CONFLICT OF INTEREST DISCLOSURES

The authors have no conflicts of interest to declare.

\section{AUTHOR AFFILIATIONS}

*Adrian College, Adrian, MI, USA; ${ }^{+}$University of Tampa, Tampa, FL, USA.

\section{REFERENCES}

Baron, R. M., \& Kenny, D. A. (1986). The moderator-mediator variable distinction in social psychological research - conceptual, strategic, and statistical considerations. Journal of Personality and Social Psychology, 51(6), 1173-1182.

Brzozowski, J. A., Taylor-Butts, A., \& Johnson, S. (2006). Victimization and offending among the Aboriginal population in Canada. Juristat Canadian Centre for Justice Statistics. Statistics Canada - Catalogue no. 85-002-XIE, Vol. 26, no. 3.

Cao, L., \& Maume, D. J., Jr. (1993). Urbanization, inequality, lifestyles and robbery: A comprehensive model. Sociological Focus, 26(1), 11-26.

Cohen, L. E., \& Felson, M. (1979). Social change and crime rate trends: A routine activity approach. American Sociological Review, 44, 588-608

Cohen, L. E., Kluegel, J. R., \& Land, K. C. (1981). Social inequality and predatory criminal victimization: An exposition and test of a formal theory. American Sociological Review, 4615), 505-524.

Daly, M., Wilson, M., \& Vasdev, S. (2001). Income inequality and homicide rates in Canada and the United States. Canadian Journal of Criminology, 43, 219

Dickson-Gilmore, E. J., \& La Prairie, C. 2005. Will the circle be unbroken?: Aboriginal communities, restorative justice, and the challenges of conflict and change. University of Toronto Press.

Farrell, G., \& Bouloukos, A. C. (2001). International overview: A crossnational comparison of rates of repeat victimization. Crime prevention studies, 12, 5-26.

Farrell, G., \& Pease, K. (2007). Crime in England and Wales: More violence and more chronic victims. Civitas Review, 4(2), 1-6.

Farrell G., Phillips, C., \& Pease, K. (1995). Like taking candy: Why does repeat victimization occur? British Journal of Criminology Summer, $35(3), 384-399$

Farrell, G., \& Sousa, W. (2001). Repeat victimization and hot spots: The overlap and its implications for crime control and problem-orientated policing. Crime Prevention Studies, 12, 221-240.

Farrell, G., Tseloni, A., \& Pease, K. (2005). Repeat victimization in the ICVS and the NCVS. Crime Prevention and Community Safety, 7, 7-18.

Feinberg, S. E. (1980). Statistical modelling in the analysis of repeat victimization. In S. E. Feinberg and A. J. Reiss (Eds.), Indicators of crime and criminal justice: Quantitative studies (pp. 143-156). Washington, DC: U.S. Bureau of Statistics.

Felson, M., \& Clarke, R. V. (1998). Opportunity makes the thief. Police Research Series, Paper 98. Policing and Reducing Crime Unit, Research, Development and Statistics Directorate. London: Home Office.

Forrester, D., Frenz, S., O'Connell, M., \& Pease, K. (1990). The Kirkholt burglary prevention project: Phase II. Crime Prevention Unit Paper 23. London: Home Office.

Fox, K. A., Nobles, M. R., \& Piquero, A. R. (2009). Gender, crime victimization and fear of crime. Security Journal, 22(1), 24-39.

Gabor, T., \& Mata, F. (2004). Victimization and repeat victimization over the life span: A predictive study and implications for policy. International Review of Victimology, 10(3), 193-221.

Gannon, M., \& Mihorean, K. (2004). Criminal victimization in Canada, 2004. Juristat - Canadian Centre for Justice Statistics. Statistics Canada - Catalogue no. 85-002-XPE, Vol. 25, no. 7.

Gotfredson, M. R. (1984). Victims of crime: The dimensions of risk. Home Office Research Study 81. London: HMSO. 
Herek, G. M. (1990). The context of anti-gay violence: Notes on cultural and psychological heterosexism. Journal of Interpersonal Violence, 5(3), 316-333.

Hindelang, M., Gottfredson, M. R., \& Garafalo, J. (1978). Victims of personal crime. Cambridge, MA: Ballinger.

Jensen, G., \& Brownfield, D. (1986). Sex, lifestyles, and victimization: Beyond routine activity. Violence and Victims, 1(2), 85-99.

Johnson, S. D. (2008). Repeat burglary victimization: a tale of two theories. Journal of Experimental Criminology, 4(3), 215-240.

Johnson, S. D., Bowers, K., \& Hirschfield, A. (1997). New insights into the spatial and temporal distribution of repeat victimization. British Journal of Criminology, 37(2), 224-241.

Johnson, S. D., Guerette, R. T., \& Bowers, K. J. (2012). Crime displacement and diffusion of benefits. The Oxford Handbook of Crime Prevention, 337.

Johnson, J. H., Kerper, H. B., Hayes, D. D., \& Killenger, G. G. (1973). The recidivist victim: A descriptive study. Criminal Justice Monograph, 4/1. Huntsville: Institute of Contemporary Corrections and the Behavioural Sciences, Sam Houston State University.

Johnson, H., \& Sacco, V. F. (1995). Researching violence against women: Statistics Canada's national survey. Canadian Journal of Criminology, $37,281$.

Lauritsen, J. L., Gatewood Owens, J., Planty, M., Rand, M. R., \& Truman, J. L. (2012). Methods for counting high-frequency repeat victimizations in the national crime victimization survey. U.S. Department of Justice. Office of Justice Programs. Bureau of Justice Statistics, April, NCJ 237308

Lauritsen, J. L., Laub, J. H., \& Sampson, R. J. (1992). Conventional and delinquent activities: Implications for the prevention of violent victimization among adolescents. Violence and Victims, 7(2), 91-108.

Lauritsen, J. L., \& Quinet, K. F. D. (1995). Repeat victimization among adolescents and young adults. Journal of Quantitative Criminology, $11(2), 143-166$.

Laycock, G. (2001). Hypothesis-based research: the repeat victimization story. Criminology and Criminal Justice, 1(1), 59-82.

Levy, M. P., \& Tartaro, C. (2009). Repeat victimization: A study of auto theft in Atlantic City using the WALLS variables to measure environmental indicators. Criminal Justice Policy Review. doi.org/ $10.1177 / 0887403409350190$

Lochner, L., \& Moretti, E. (2004). The effect of education on crime: Evidence from prison inmates, arrests, and self-reports. American Economic Review, 94(1), 155-189.

Long, J. S., Freese, J., \& Long, J. S. (1997). Regression models for categorical and limited dependent variables. India: Sage Publications.

Menard, S., \& Huizinga, D. (2001). Repeat victimization in a high-risk neighborhood sample of adolescents. Youth \& Society, 32(4), 447-472.

Miethe, T. D., Stafford, M. C., \& Long, J. S. (1987). Social differentiation in criminal victimization: A test of routine activities/lifestyle theories. American Sociological Review, 184-194.

Nazaretian, Z., \& Merolla, D. M. (2013). Questioning Canadian criminal incidence rates: A re-analysis of the 2004 Canadian victimization survey. Canadian Journal of Criminology and Criminal Justice/ La Revue canadienne de criminologie et de justice pénale, 55(2), 239-261.

Pease, K. (1993). Individual and community influences on victimization and their implications for crime prevention. In D. P. Farrington, R.
J. Sampson, \& P.-O. Wikstrom (Eds.), Integrating individual and ecological aspects of crime (pp. 323-338). Stockholm: National Council for Crime Prevention.

Peterson, R. D., \& Krivo, L. J. (1999, September). Racial segregation, the concentration of disadvantage, and black and white homicide victimization. Sociological Forum, 14(3), 465-493.

Perreault, S., \& Brennan, S. (2010). Criminal victimization in Canada, 2009. Juristat: Canadian Centre for Justice Statistics, 30(2), 1G.

Planty, M., \& Strom, K. 2007. Understanding the role of repeat victims in the production of annual US victimization rates. Journal of Quantitative Criminology, 23(3), 179-200.

Polvi, N., Looman, T., Humphries, C., \& Pease, K. (1990). Repeat breakand-enter victimisation: Time course and crime prevention opportunity. Journal of Police Science and Administration, 17(1), 8-11.

Ratcliffe, J. H. (2004). The hotspot matrix: A framework for the spatiotemporal targeting of crime reduction. Police Practice and Research, $5(1), 5-23$.

Reiss, A. J. (1980). Victim proneness in repeat victimization by type of crime. In S. E. Feinberg \& A. J. Reiss (Eds.), Indicators of Crime and Criminal Justice: Quantitative Studies (pp. 41-53). Washington, DC: U.S. Bureau of Statistics.

Reitz, J. G., \& Banerjee, R. (2007). Racial inequality, social cohesion and policy issues in Canada. Canada: Institute for Research on Public Policy.

Sampson, R. J., \& Laub, J. H. (2003). Life-course desisters? Trajectories of crime among delinquent boys followed to age 70. Criminology, $47(3), 555-592$

Short, M. B., Brantingham, P. J., Bertozzi, A. L., \& Tita, G. E. (2010). Dissipation and displacement of hotspots in reaction-diffusion models of crime. Proceedings of the National Academy of Sciences, 107191, 3961-3965.

Sparks, R. F., Genn, H. G., \& Dodd, D. J. (1977). Surveying victims: A study of the measurement of criminal victimization, perceptions of crime, and attitudes to criminal justice. Wiley.

Statistics Canada. 2004. General Social Survey, 2004 Cycle 18 Victimization Main Survey - Questionnaire Package. Social and Aboriginal Statistics Division.

Statistics Canada. 2009. General Social Survey, 2009 Cycle 23 Victimization Main Survey - Questionnaire Package. Social and Aboriginal Statistics Division.

Tilley, N. (1993). The prevention of crime against small businesses: The safer cities experience. Crime Prevention Unit Paper 45. London: Home Office.

Tilley, N., Laycock, G., \& Webb, B. (2002). Working out what to do: Evidence-based crime reduction. London: Home Office.

Tseloni, A., \& Pease, K. (2003). Repeat personal victimization. "Boosts" or "Flags"? British Journal of Criminology, 43(1), 196-212.

Tseloni, A., Wittebrood, K., Farrell, G., \& Pease, K. (2004). Burglary victimization in England and Wales, the United States and the Netherlands: A cross-national comparative test of routine activities and lifestyle theories. British Journal of Criminology, 44(1), 66-91.

Ybarra, L. M., \& Lohr, S. L. (2002). Estimates of repeat victimization using the National Crime Victimization Survey. Journal of Quantitative Criminology, 18(1), 1-21.

Zeigenhagen, E. 1976. The recidivist victim of violent crime. Victimology, $1,538-550$ 